\title{
RETÓRICA E CIÊNCIA: O CASO DA LINGÜÍSTICA CRÍTICA
}

\author{
Rhetorics and Science: the case of Critical \\ Linguistics
}

\author{
Rodrigo Tadeu Gonçalves* \\ Alessandro J. Beccari"*
}

\section{INTRODUÇÃo}

Há duas maneiras mais ou menos estáveis de a relação entre ciência e sociedade ocorrer: ou algo é "científico" e, portanto, atestadamente verdadeiro, ou o cientista defende posições que parecem tão claramente contra-intuitivas ao leigo que, naturalmente, este último prefere ignorar o que lhe parecem "devaneios" do especialista. Este artigo tenta ilustrar a aparente e alegada incapacidade de um grupo de cientistas contemporâneos, a saber, os cientistas da linguagem, de defenderem sua auto-proclamada soberania no que tange aos assuntos concernentes a um bem humano universal, a linguagem (cf. RAJAGOPALAN, 2003; SILVA; RAJAGOPALAN, 2004). O percurso desse artigo é o de, através de uma brevíssima história crítica da retórica no ocidente, mostrar como a ciência moderna falha ao escolher estratégias retóricas para conquistar seu espaço, uma vez que, ainda para muitos, mesmo depois de filósofos da ciência como K. Popper $(1972 ; 1982)$ e T. Kuhn $(2003)$ terem relativizado o suposto truísmo de que a ciência é capaz de atingir e produzir verdades incontestáveis, o papel do cientista ainda é, para muitos deles, o de "portador da verdade". Mostraremos como, de certa forma, o debate em torno da proposta da lingüística crítica como proposto por Rajagopalan é, de uma certa maneira, uma reedição do debate milenar entre especialistas detentores da verdade e sofistas/retóricos.

Professor da Área de Letras Clássicas - DLLCV (UFPR).

Mestrado em Letras - Estudos Lingüísticos (UFPR). 


\title{
2 A Retórica Antes da CiÊnCIA Moderna
}

Platão fundou a tradição da busca da verdade através da observação e reflexão distanciadas dos fenômenos do mundo. Essa procura disciplinada pelo que realmente está ali, id quod est, deu origem à idéia de que o homem de ciência (no sentido abrangente do termo) não tem nenhuma obrigação de convencer ninguém de que está no caminho certo ou, inversamente, de ouvir a opinião do vulgo. Platão contrapôs uma filosofia absolutista, conhecida por poucos, a uma filosofia da relatividade, que é experimentada por muitos em seu dia-a-dia. Para se entender a maneira como Platão despreza a retórica, veja-se a seguir, o que ele diz em Górgias a respeito do tipo de conhecimento que a retórica possibilita:

\begin{abstract}
A retórica é um agente do tipo de persuasão \{peithous demiurgos\} que busca produzir convicção, mas não educar as pessoas sobre questões referentes ao certo e ao errado [...] Um retórico, então, não está preocupado em educar as pessoas reunidas em tribunais sobre o certo e o errado; tudo que lhe interessa é persuadir $\{$ peistikos\}. Ou seja, eu não deveria pensar que é possível para ele fazer com que tantas pessoas entendam \{didaxai $\}$ tantas questões importantes num prazo tão curto (PLATÃO ${ }^{1}$, apud LATOUR, 2001, p. 277).
\end{abstract}

Bruno Latour (2001, p. 277), em seu livro A Esperança de Pandora, quer demonstrar como Platão distingue o discurso persuasivo, peistikós, do retor, do discurso didático do filósofo. Para ele, o discurso didático é superior ao persuasivo porque realmente tem a possibilidade de começar a ensinar seu auditório sobre algum fato verdadeiro e não meramente especulativo ou, pior, que leve em conta opiniões de pessoas sem conhecimento no assunto. Segundo Latour (2001, p. 277), o que Sócrates não entende é que "[o] 'demiurgo da persuasão' faz exatamente o que o anseio 'didático' não pode fazer: ele lida com as próprias condições de urgência com as quais a política se defronta". Ou seja, Platão exige do retor que se transforme num professor que pede a seu auditório que se transforme em uma sala de aula que repita mecanicamente algo que o mestre conhece de antemão e que precisa apenas ser assimilado mecanicamente. Entretanto, esse tipo de atividade não corresponde aos reais problemas de uma comunidade que constantemente se defronta com novas dificuldades que exigem respostas rápidas e cujas soluções não podem ser relegadas a uma

PLATÃo, Górgias, p. 454e-455a. 
elite intelectual que medite sobre elas na reclusão tranqüila e segura de suas academias. Ao que parece, a ciência contemporânea herdou da tradição platônica, por um lado, uma forte tendência a esse tipo de visão alienada das contingências do dia-a-dia e, por outro, um desprezo pela opinião pública em relação a seus empreendimentos científicos.

Infelizmente, só se conhecem os sofistas através de seus inimigos. Além do Górgias, Platão escreveu mais dois livros sobre retórica: o Protágoras e o Teeteto. No Protágoras, a personagem de mesmo nome defende suas idéias sobre o ser humano e a respeito do discurso retórico. Para o Protágoras histórico, que viveu entre 486 a.C. e 410 a.C., a dialética é uma erística (discurso controvertido). Para ele, existiriam duas regras básicas para todo discurso desse tipo: a) todo assunto pode ser sustentado ou refutado; b) a todo argumento pode-se opor outro. E, além dessas duas regras, um princípio que os renascentistas iriam retomar a seu modo: o homem é a medida de todas as coisas. Ou seja, "[...] as coisas são como aparecem a cada homem (ou a cada grupo de homens que concordem em como as coisas são); não há outro critério de verdade (porque todos são fabricados)" (REBOUL, 2000, p. 8). A partir destas regras e deste princípio (entendido como acordo entre interlocutores), fica implícito que é a comunidade que decide o que é verdade ou não, i.e., todos os valores e convenções estão relacionados a lugares e situações. Portanto, para Protágoras, assim como para os outros sofistas, era evidente que verdades e poderes andam juntos e são necessariamente transitórios. Nesse sentido, o único critério do discurso humano é o sucesso. Platão e sua escola não podem aceitar tal alargamento do debate.

Aristóteles escreveu um texto que hoje recebe o nome de Retórica. A marca registrada e inovadora de Aristóteles foi imprimir ao estudo da retórica duas características próprias do gênio grego: a observação e o espírito sistemático. Para Aristóteles, a retórica é uma ferramenta que pode ser útil no mundo jurídico, na prosa literária, na filosofia e no ensino, mas que, em si mesma, é indiferente: pode servir tanto ao bem quanto ao mal: é um bem que, como a força, a saúde ou a riqueza, pode ser usado para o proveito ou para a ruína dos seres humanos. Duas teses podem ser igualmente persuasivas, mas isso não significa que sejam equivalentes: Aristóteles não nega a existência do bom e do justo como bens absolutos, mas ele afirma que muitas vezes a ignorância e a inaptidão não permitem que a verdade prevaleça sobre a mentira, e é por isso que ele defende o ensino da retórica. Seu aprendizado é importante porque proporciona ao cidadão que se sente lesado ou agredido, ou que deseja expor suas idéias sobre qualquer assunto - como o bem comum, a religião ou as colheitas -, um método que lhe permita argumentar em defesa de seu ponto de vista na presença de qualquer 
público. No pensamento aristotélico, a retórica é um instrumento imprescindível na formação do homem universal. Inversamente, é impossível a qualquer pessoa dominar a retórica sem uma ótima educação geral.

Os romanos consideram a retórica uma arte completamente funcional. É em Roma que, pela primeira vez, diferencia-se o professor de retórica do orador. A palavra grega rhetor significava tanto o executante de um discurso, que os latinos chamam de orator, quanto aquele que ensina a arte e que recebe o nome de rhetor, em latim. Isso se deu, talvez, pelo grande número de escravos pedagogos de origem grega no Império e por serem oradores oficiais apenas os cidadãos romanos.

\section{A CiÊnCIA ModERna E A RETóRICA DAS CiÊnCIAS EXATAS}

Por volta do século XVI, os espíritos inquisitivos dos cientistas da época passam a praticar uma ciência de base fortemente empirista. Galileu, Copérnico e Kepler, por exemplo, contrariam fortemente o senso comum com hipóteses aparentemente radicais que passam a ser corroboradas através de dados brutos da realidade que devem ser medidos, quantificados, separados e classificados. Assim, a astronomia pode se dizer certa de que nós, leigos, estamos todos errados na nossa intuição de que o Sol gira ao redor da Terra: os cálculos realizados a partir de medições e observações demonstram que somente o contrário pode ser verdadeiro: sabemos hoje que a Terra gira em torno do Sol, e que nossa "impressão" sensorial nos engana ao mostrar-nos parados sobre a Terra parada e ao mostrar-nos um Sol que todos os dias vem e vai. Assim, surge a maneira moderna de fazer ciência: uma hipótese levantada precisa de dados empíricos para ser finalmente comprovada, o que constitui o chamado indutivismo. O contrário, o dedutivismo de orientação mais racionalista, também serve para derivar das premissas científicas já dadas outras verdades tão científicas quanto. $O$ século XIX vê o surgimento do movimento científico-filosófico do positivismo, que se radicaliza com o neo-positivismo do Círculo de Viena da primeira metade do século XX. Para estes últimos filósofos, a empresa científica visa buscar as verdades sobre a natureza na comprovação empírica rigorosa, regulada, neutra e isenta da interferência de ruídos que pudessem atrapalhar o cientista no seu caminho pela verdade.

Somente a partir da primeira metade do século XX, com pensadores como Karl Popper $(1972 ; 1982)$, é que essa maneira aparentemente perfeita e ideal de fazer ciência começa a sofrer duros golpes. Popper defende a posição de que nenhuma hipótese pode ser comprovada empiricamente através da avaliação das evidências que lhe dão suporte. E ele mostra isso através da impossibilidade lógica de se comprovar com toda a certeza que 
uma conclusão verdadeira decorra necessariamente de uma premissa verdadeira, pois, logicamente, uma conclusão verdadeira também pode decorrer de uma premissa falsa. Assim, uma hipótese só pode ser refutada, nunca comprovada. Portanto, a "verdade" passa a se parecer muito mais com "verossimilhança" do que os positivistas empiristas gostariam. Dessa forma, para Popper, o nosso conhecimento resulta necessariamente finito, sendo infinita apenas a nossa ignorância. Essa revolução no pensamento sobre a ciência se segue de teses ainda mais fortemente contrárias ao espírito limitado do positivismo, como as teses de Kuhn (2003), Feyerabend (2007), Lakatos (1976) e Latour (2001).

Curiosamente, muitos dos cientistas ainda hoje, até mesmo nas ciências humanas, acreditam estar agindo cientificamente através de metodologia rígida em busca de "verdades".

O trabalho do pesquisador é tanto adaptar novos fatos a um sistema pré-estabelecido quanto tentar fazer com que dados antigos se combinem mais harmonicamente dentro de um sistema antigo. Nesse sentido, assim como no discurso filosófico ou político, há também uma preocupação com determinados juízos de valor no trabalho científico. As decisões de um cientista quase nunca vão contra os valores estabelecidos aceitos pela comunidade científica do seu campo de pesquisas particular. Suas descobertas podem, algumas vezes, parecer incompatíveis com seu modelo teórico e com a teoria da tradição a que pertencem, mas, antes de questionar seus parâmetros, o cientista procurará por todos os meios possíveis assimilar os novos fenômenos àquilo que já se sabe sobre determinado aspecto da realidade. Ou seja, cada vez que um fato novo desorganiza um determinado saber, o cientista tentará: 1) ou reorganizar todo o saber antigo para que esse elemento novo seja assimilado, 2) ou "modificar" o fato novo para que se encaixe no antigo arcabouço teórico. Nesse processo, cria-se um saber reformulado que não só integra um fenômeno inusitado, mas também fica mais aberto para os novos fatos que virão a seguir. Ou seja, a pesquisa científica está inserida no contexto de uma comunidade tradicional da qual todo cientista participa e para a qual tem que se dirigir cada vez que necessita de comprovação para suas teses. Portanto, todo o esforço criativo científico, embora muito limitado, busca, no fim das contas, a adesão de um auditório universal - exatamente o que todo bom orador tem sido ensinado a fazer desde os tempos dos velhos sofistas.

\section{CiÊnCIA E RetóRICA: O CASO da Lingüística CRítica}

Como tentativa de ilustrar a relação entre ciência e retórica, analisaremos um debate contemporâneo na área da lingüística, uma ciência 
tradicionalmente inserida no contexto das humanidades, mas que, amiúde, procura fundamentar suas teorias em bases metodológicas parecidas com as das ciências naturais, chamadas "duras", pressupondo um acesso à verdade científica parecido com o que supunham conseguir os neopositivistas do Círculo de Viena.

Um tema que nos parece bastante apropriado para exemplificar os problemas advindos da relação conflituosa entre cientistas profissionais da linguagem e o chamado público "leigo" é a questão dos estrangeirismos. As influências entre as línguas se dão de maneiras bastante complexas e, na atual ordem mundial, o que se vê é uma crescente influência da língua inglesa como língua de prestígio na maior parte do globo terrestre. O modo de ver a questão por parte dos lingüistas tem sido bastante discutido, em virtude de a maioria dos lingüistas preocupados com a questão da língua em âmbito sócio-político saber que influência não significa necessariamente perigo, e que empréstimos vocabulares e influência estrangeira não são causadores da decadência ou da morte das línguas mas, pelo contrário, são fatores que enriquecem o léxico e auxiliam no processo de mudança lingüística, inerente à maneira de ser de qualquer uma das línguas naturais.

O ponto de vista purista sobre a língua, que muitas vezes recebe maior apoio popular, defende a tese de que a língua é um bem que deve ser preservado na sua integridade, que deve ser defendido de ataques estrangeiros, como um símbolo nacional que não se pode alterar ou modificar, sob pena de diminuir a soberania da nação ou de contaminar a pureza da língua. Por estranho que pareça, o ponto de vista leigo que apóia esse ponto de vista conservador aparentemente não consegue perceber as implicações óbvias de uma postura como essa. Assim, a idéia de que o português é aparentado do latim, que por sua vez descende de outra língua, parece não bastar para mostrar aos puristas que a evolução lingüística é natural e que o que chamamos de "português" hoje não seria nada caso não tivesse acontecido o que se poderia chamar, sob o ponto de vista desses mesmos puristas, de uma contaminação seguida de decadência de uma outra língua, ou do que um dia foi o latim.

Deixando de lado a defesa de qualquer um dos dois lados da discussão, passemos ao caso que melhor ilustra o embate entre especialistas e leigos quanto a esse tema: o projeto de lei 1.676 de 1999, proposto pelo então deputado federal Aldo Rebelo. Resumidamente, o que o projeto previa eram sanções e multas para quem fizesse uso de vocabulário estrangeiro ao usar a língua portuguesa, após uma espécie de período de "adaptação". Assim, com a justificativa de defender a integridade nacional, o texto do projeto, que chegava a soar perigosamente extremista, causou uma discussão bastante acirrada em vários âmbitos e, por fim, acabou por ser preterido, de 
modo que em seu lugar foi proposto um substitutivo mais brando do então deputado Amir Lando em 2002, melhor recebido pelos lingüistas.

Kanavilil Rajagopalan, em suas publicações recentes (RAJAGOPALAN, 2003; SILVA; RAJAGOPALAN, 2004), vem defendendo o que ele chama de "lingüística crítica", uma proposta de novas tomadas de posições políticas e o que ele chama de "exames de consciência" por parte dos lingüistas para que sua atividade como cientista possa ser mais relevante para a sociedade. Longe de colocar em questão a validade da proposta, analisaremos os argumentos utilizados por Rajagopalan.

Bruno Latour (2001), em um livro que se propóe a responder à pergunta "você acredita na realidade?", detém-se na análise da antiga questão sobre a relação entre força e razão, ou ainda, de certa maneira, entre política e ciência, que emerge sempre que volta à tona a discussão sobre a verdade derivável das teorias científicas, sobre a superioridade do conhecimento dito científico em contraposição ao conhecimento do leigo, do senso-comum. A discussão tem um dos seus pontos culminantes já na Antigüidade, no já mencionado Górgias de Platão. O que Latour nos mostra é que os retóricos se opõem aos peritos, pois aqueles defendem o chamado conhecimento epidêitico, ou seja, a demonstração baseada em recursos e floreios de linguagem, enquanto estes defendem o conhecimento apodêitico, ou seja, a demonstração matemática, supostamente inabalável, já que racional e universal. Sócrates, ao defender o conhecimento apodêitico, quer mostrarnos que, através de uma demonstração matemática passo-a-passo, não há como discordar da verdade a que se chega. Assim, para Sócrates, o conhecimento epidêitico nada mais é do que conviç̧ão sem compreensão, diferente do conhecimento verdadeiro do especialista (Górgias, p. 454e).

Latour dá tanta importância ao Górgias exatamente porque a defesa do conhecimento apodêitico é a base do que chamamos de conhecimento científico ocidental. Não há como negar uma conclusão derivada logicamente de premissas dadas (os chamados axiomas). As teorias científicas buscam, então, ao longo dos séculos, as "verdades" por trás das coisas, e as buscam através do argumento da razão, das leis naturais imutáveis. Por isso o conhecimento do leigo, o conhecimento derivado de convencimento, de convenção, do uso, da práxis, pouco ou nada pode dizer ao especialista que busca as verdades. Dessa forma, o conhecimento derivado do senso comum nada tem a acrescentar às teorias científicas. Nem mesmo o que parece aos sofistas o maior atrativo de sua arte, o fato de que você só precisa aprender a oratória para saber falar e convencer sobre qualquer coisa, abala as convicções de Sócrates: 
Isso não simplifica as coisas, Sócrates? A retórica é a única arte que você precisa aprender. Você pode ignorar tudo o mais e ainda assim tornar-se o melhor dos profissionais (Górgias, p. 459c).

Tentaremos ver na discussão de Lopes da Silva \& Rajagopalan (2004) uma espécie de reedição do debate entre Cálicles, sofista aliado a Górgias no diálogo platônico em questão, e Sócrates, para analisar, em última instância, até que ponto os lingüistas podem ser bons retóricos ou até que ponto os especialistas podem ter força política.

A obra acima citada parte da iniciativa de Fábio Lopes da Silva de traduzir um artigo de Rajagopalan que fora publicado no periódico Language and Politics, em inglês, para aproximar do público brasileiro o debate que o referido texto suscitava: a idéia de que a ciência da linguagem teria feito falharem os próprios lingüistas na sua tentativa de serem reconhecidos como os especialistas da linguagem. A posição é bastante polêmica e complexa, e referimos os leitores interessados à leitura das obras mais recentes de Rajagopalan já mencionadas, que sintetizam o assunto, seu livro de 2003 e esse livro-debate organizado por Lopes da Silva e Rajagopalan. Neste livro, depois da tradução do texto principal, os organizadores o enviaram a diversos lingüistas profissionais, políticos, alunos de pós-graduação de áreas afins, gramáticos tradicionais e leigos, que o comentaram, e que, por fim, receberam uma réplica de Rajagopalan. Tudo foi, então, editado no mesmo livro, o que nos dá material abundante para tentar entender a dinâmica das guerras da ciência na lingüística ou em assuntos relacionados com a língua.

A idéia principal de Rajagopalan é a de que os lingüistas são incapazes de se fazer ouvir pela sociedade quando julgam que algo de relevante sobre a língua deve ser discutido. A questão relevante neste caso, como já explicamos, é a questão do projeto de lei de Aldo Rebelo contra os estrangeirismos. Os lingüistas, julgando que, por serem os únicos especialistas da linguagem, deveriam ter posição de destaque no debate que deveria se seguir à proposta do projeto, antes que ele fosse aprovado, acabaram se mostrando incapazes de convencer a opinião pública de que suas posições sobre a linguagem deveriam ser levadas em conta. Sem discutir se Rajagopalan tem razão (outros lingüistas, como Carlos Alberto Faraco (SILVA; RAJAGOPALAN, 2004), discordaram dele e argumentaram bastante plausivelmente. Indicamos a leitura do livro para os interessados em ver como essa questão não se resolve tão facilmente), o que parece interessante é ver como aparentemente os lingüistas se posicionam do lado de uma suposta "verdade" quanto ao assunto em pauta: a linguagem.

Rajagopalan justifica assim a necessidade de o lingüista conseguir se fazer ouvir como verdadeiro especialista da linguagem: 
Há um adágio popular que diz que de médico e de louco todo mundo tem um pouco. Graças ao projeto Aldo Rebelo, parece que logo será apropriado acrescentar uma terceira figura a essa dupla: o lingüista. Para cada lingüista profissional trancafiado em seu gabinete ou fazendo trabalho de campo em regiões remotas e quase inacessíveis, existem literalmente milhares de lingüistas amadores pelas ruas, clamando por serem escutados e tão convencidos de seus pontos de vista quanto qualquer um de seus "colegas" institucionalmente autorizados nos campi (SILVA; RAJAGOPALAN, 2004, p. 20).

Diferentemente do que pode parecer pela leitura deste trecho, Rajagopalan não propõe um isolamento do cientista da linguagem, detentor do verdadeiro conhecimento apodêitico, da sociedade que o cerca, com seus muitos "lingüistas, médicos e loucos". Ao contrário, o autor sustenta que uma aproximação entre o ponto de vista do especialista e os anseios, crenças e opiniões do grande público leigo poderiam trazer mais benefícios do que o cientista mais radicalmente positivista e "socrático" imagina. Esta é, inclusive, uma das propostas da chamada "lingüística crítica" defendida por Rajagopalan. No entanto, uma proposta como esta é muito difícil de ser colocada em prática, visto que se sabe que a ciência progride às expensas do conhecimento popular, que, por sua vez, acaba tendo que se adaptar ao que o cientista descobre. No caso da lingüística, num debate tão complexo quanto o que cerca a questão dos estrangeirismos, é bastante difícil para o público geral aceitar a posição dos lingüistas que gritam em coro coisas que soam para os políticos, retóricos e povo como "deixem a língua em paz", "a língua cuida de si mesma", "não há certo e errado, portanto fale como quiser" ${ }^{2}$, e outras pérolas mal-digeridas do pensamento lingüístico contemporâneo que, em virtude de supostas falhas de capacidade de relacionamento com o público, os lingüistas acabam por disseminar na sociedade. Assim, as políticas sobre a língua costumam ser resolvidas por comissões que envolvem gramáticos de orientação normativista, ou ainda

Esta máxima resulta de anos de pesquisa sociolingüística mal-compreendidos pelos gramáticos, professores de língua portuguesa e público leigo: aquilo que deveria ser capaz de gerar a reflexão sobre os níveis de linguagem, dialetos, variação regional, social, etária e de gênero, acaba por ser entendida fora dos círculos da academia como uma posição extremamente liberal de quem quer "abolir as regras", para quem "não é mais necessário se falar em certo e errado". Não é necessário dizer que a necessidade que o público geral tem por algum tipo de sistematização (inclusive em virtude da inclusão de tantas horas semanais de ensino de língua materna nas escolas de educação básica) e de normativização torna o discurso tradicionalista muito mais aceitável e digno de crédito do que o discurso aparentemente louco, "vale-tudo" ou "oba-oba", dos lingüistas, que, em decorrência disso, torna-se altamente indesejável. Tudo isso, segundo a argumentação presente no texto gerador da polêmica de Silva; Rajagopalan (2004), seria culpa da própria incapacidade de os lingüistas se afirmarem como verdadeiros especialistas da linguagem, que gera a falta de respeito que a sociedade demonstra por suas opiniões. 
"imortais" da Academia Brasileira de Letras (que incluem, em suas fileiras, escritores de estrondoso sucesso comercial e discutível qualidade literária, como Paulo Coelho).

Colocada nestes termos, a discussão traz novamente à tona uma disputa que costuma ser o centro das atenções dos debates entre a lingüística como ciência e a tradição de pensamento sobre a linguagem que não apresenta a cientificidade que a lingüística moderna angariou desde o seu surgimento, em níveis cada vez mais acentuados. Essa progressão de graus de cientificidade pode ser ilustrada pela maneira como os Junggrammatiker do final do século XIX acusavam a lingüística histórico-comparativa de até então como sendo pouco científica e pouco rigorosa em seus métodos, de maneira a ocasionar uma mudança de pensamento que levou a lingüística a patamares cada vez mais rigorosos do ponto de vista da busca pela verdade científica, passando por Bloomfield e seu positivismo excessivamente empirista, Chomsky pelo seu renascimento racionalista no pensamento sobre a linguagem e pelos lingüistas de formação lógico-matemática que começam a ganhar força a partir de Frege, Russell, Wittgenstein e de alguns neopositivistas como Carnap, Ajdukjevicz e Tarski (ROBINS, 1981; MOUNIN, 1970, KOERNER; ASHER, 1995).

Mesmo quando o cientista coloca a distinção entre tradição gramatical e ciência da linguagem em termos de tipos de conhecimentos diferentes, que não são necessariamente concorrentes, pois são construídos de maneira diferente e para propósitos diferentes, pode ficar a impressão de que, respeitadas essas distinções fundamentais, o que resta é: um conhecimento, por ser científico, é mais legítimo, e o outro, tradicional, acaba sendo menos respeitado e descartado.

Assim, podemos analisar a seguinte seqüência de argumentos que Rajagopalan utiliza para ilustrar a questão:

Uma coisa foi ficando cada vez mais clara para os lingüistas profissionais no Brasil em meio a todo o episódio envolvendo a lei Aldo Rebelo: eles foram completamente alijados no processo decisório e em vão empreenderam grandes esforços para que suas vozes fossem ouvidas pelos que verdadeiramente detêm o poder de decisão. Reconhecem os lingüistas que eles não apenas foram postos de lado na discussão. Na verdade, seus pontos de vista ou foram ignorados por aqueles cujas opiniões importam, ou - o que é ainda pior - estão simplesmente sendo preteridos em detrimento das posições manifestas pelos gramáticos tradicionais - seus arquiinimigos -, que há muito tempo gozam de alta estima na sociedade brasileira (e, de fato, no resto do mundo) (SILVA; RAJAGOPALAN, 2004, p. 26). 
Ora, as palavras de Rajagopalan soam muito parecidas com as de alguém que acha que aquele que detém o conhecimento verdadeiro é o que deve agir de maneira mais adequada e ser ouvido com respeito em alguma situação em que isso signifique algo realmente importante. No entanto, como reclama Rajagopalan, historicamente, quem costuma ser ouvido é o gramático tradicional, mais afinado com as necessidades do grande público, por defender a posição (tida pelos lingüistas como anti-científica) de que a língua precisa de protetores, guardiões, regras rígidas e distantes de teorias estranhas ao senso comum, como as que os lingüistas defendem. Curiosamente, o sofista Górgias, argumentando contra Sócrates, defende a seguinte posição:

\begin{abstract}
Górgias. [...] Mencionarei uma grande prova [em favor da retórica]; tenho acompanhado meu irmão e outros médicos à casa de doentes que se recusam a ingerir as poções, ou não permitem ao médico a intervenção cirúrgica ou o cautério; muitas vezes o médico não logra convencê-los, mas eu sim, apenas com a arte da oratória. Suponhamos fossem a uma cidade, à tua escolha, um orador e um médico e tivessem de disputar, na assembléia do povo ou em qualquer outro congresso, qual dos dois deveria ser eleito médico; o médico, asseguro-te, ficaria completamente apagado e seria eleito o capaz de falar, se assim quisesse. Se competir o orador com qualquer outro profissional, nenhum persuadirá melhor do que ele a escolha de sua pessoa, pois não há matéria sobre a qual não fale à multidão mais convincentemente do que um profissional, seja quem for (Górgias, p. 456a-c).
\end{abstract}

o que percebemos é que, desde a Antigüidade, aqueles que buscam o conhecimento mais "sólido" (apodêitico) sofrem com a dificuldade de se fazerem ouvir pelos leigos, pelo grande público. Assim, aproximando os gramáticos tradicionais dos sofistas, que conquistam mais facilmente a opinião pública e acabam sendo ouvidos pelos tomadores de decisões, podemos identificar o lingüista descrito por Rajagopalan como um socrático em busca da verdade. Diferentemente de Sócrates, contudo, a queixa dos lingüistas, corroborada pela opinião de Rajagopalan expressa acima, é a de que eles não são capazes de se fazer ouvir pela multidão.

Em dias de exaltada ciência positiva produtora de curas, vacinas, soluções tecnológicas e conforto para o homem, as chamadas ciências naturais, as ciências médicas e as ciências tecnológicas acabam por se fazer ouvir com muito mais facilidade pela multidão, uma vez que sua palavra se reveste de argumento de força dos mais bem-vistos: a chamada cientificidade. É curioso notar que basta algo ser "comprovado 
cientificamente" para ser disseminado como verdadeiro, para ser vendido, para dar mais lucro. Nas ciências humanas, no entanto, a cientificidade, muitas vezes buscada em uma tentativa de aproximar as tendências metodológicas daquelas das ciências exatas (como no caso da lingüística formalista descrita acima), parece não surtir efeito em discussões em que a voz do especialista precisa ser ouvida.

Rajagopalan concorda que haja esforços relativamente bemsucedidos na direção de conseguir visibilidade para a opinião do lingüista, ao afirmar que, por exemplo:

\begin{abstract}
Marcos Bagno e Sírio Possenti têm feito um excelente trabalho ao insistentemente bater na tecla de que a questão da linguagem é séria demais para ser deixada aos cuidados de um punhado de políticos e guardiões bem-intencionados. Mas a mensagem que muitas vezes chega ao público é elitista e parece conter um subtexto que diz: "Olhem aqui, vocês estão brincando com fogo quando fazem julgamentos apressados em assuntos lingüísticos. Deixem esses assuntos conosco - os únicos especialistas genuínos" (SILVA; RAJAGOPALAN, 2004, p. 26).
\end{abstract}

Soando de tal forma arrogantes, o que poderíamos sugerir aos lingüistas é: estudem a história da retórica, de modo que possam relembrar que já Sócrates concordava que o papel do especialista não é convencer o grande público sobre qualquer assunto, e sim buscar o convencimento do seu interlocutor sobre aquilo que ele sabe. Acompanhemos mais um pouco a argumentação, agora com uma citação de Bagno (apud SILVA; RAJAGOPALAN, 2004, p. 29):

O texto [do projeto de lei] mereceria uma demorada análise, que não podemos fazer aqui. Mas, antes de tudo, para definição de posições, é importante deixar claro que esse projeto já encontrou um elevado grau de rejeição por parte da maioria dos lingüistas e pesquisadores engajados na investigação dos fenômenos lingüísticos do Brasil. Atenção: [i] escrevi lingüistas e pesquisadores, pessoas que analisam a língua de acordo com teorias científicas consistentes, com base em coleta de dados da língua realmente utilizada pelos brasileiros, coleta feita segundo metodologias rigorosas, diversas vezes testadas e aprovadas. [ii] Não escrevi gramáticos tradicionalistas, muito menos apresentadores de programas de televisão sobre português certo e errado, nem tampouco autores de colunas de jornal e revista que dão "dicas" de "bom" português (itálicos do texto original, negritos e numeração romana nossos). 
Um olhar atento sobre essa citação de Marcos Bagno nos permite ver algumas coisas para além do que parece ser apenas uma tentativa de auto-afirmação do trabalho de um lingüista renomado e atuante na tentativa de obter "representatividade" político-social.

Em primeiro lugar, Bagno se utiliza da argumentação arrogante do especialista para conquistar legitimidade para sua ciência. Em [i], percebemos que Bagno se gaba de fazer ciência de acordo com "teorias consistentes", com base em coleta de dados autênticos de falantes brasileiros, coleta esta "rigorosa" e "feita segundo metodologias rigorosas". Para coroar, lança mão do nível mais baixo da argumentação de base positivo-racionalcientífica: "diversas vezes testadas e aprovadas". Se estivesse vendendo um produto, terminaria com um "compre já!".

Já dissemos acima que essa visão de ciência positivista-empirista de que os dados são coletados de maneira neutra e mostram a "verdade" sobre uma determinada hipótese cai por terra com os trabalhos de filósofos da ciência como Karl Popper. John Lyons (1987, p. 29), no seu importante manual para iniciantes na área da lingüística já questionava essa visão estreita de ciência:

\begin{abstract}
Na realidade, cientistas e filósofos da ciência já não aceitam mais tão unanimemente a existência de um único método de investigação, aplicável a todos os ramos da ciência. o próprio termo "método científico" tem uma aura antiquada, até mesmo do século passado. Por vezes é dito que a investigação científica deve necessariamente preceder de uma generalização indutiva com base na observação teoricamente não-controlada ${ }^{3}$. Realmente, é isso que muitos afirmam estar implicado no termo "método científico". Mas poucos são os que, mesmo nas ciências naturais, trabalham desta forma. Seja qual for o significado do conceito de subjetividade científica, ele certamente não implica que o cientista deva evitar a elaboração de teorias e a formulação de hipóteses gerais até que tenha levantado uma quantidade suficiente de dados. Os dados científicos, como diversas vezes foi indicado, não são oferecidos gratuitamente pela experiência, mas sim dela extraídos. Observação acarreta atenção seletiva. Não há observação e coleta de dados que não estejam ligados a uma teoria e a uma hipótese. Para usar uma frase da moda, que surgiu com Popper, a observação, por necessidade e desde o início, pressupõe a teoria.
\end{abstract}

\footnotetext{
BLOOMFIELD, 1935, p. 20 apud LYONS, 1987, p. 47: "As únicas generalizações úteis sobre a lingua(gem) são as indutivas".
} 
Como podemos ver, a tentativa de Bagno de angariar poder argumentativo para o lado do cientista segundo seus termos é um tanto ultrapassada, pelo menos desde Popper, Lakatos, Kuhn e Feyerabend, filósofos cujas teorias e trabalhos importantes datam de meados do século XX em diante. Dizer que suas verdades são "mais verdadeiras" porque são científicas é mais um dos argumentos baixos de quem ainda não percebeu que Popper relativizou a noção de verdade científica (referência), e que o papel de Sócrates talvez já não possa mais ser interpretado no drama do conhecimento, em virtude da extinção da noção de verdade absoluta.

Um outro ponto de importância fundamental nessa passagem é o que podemos ver em [ii]: Bagno se mostra aparentemente ressentido pelo fato de que, quando o grande público ouve algum assunto relacionado à língua, pode querer consultar os gramáticos tradicionalistas, apresentadores de televisão e escritores de colunas em jornal. Isso se mostra pela sua retomada explícita dos termos "lingüistas e pesquisadores", após um alarmante "atenção:". Ora, o argumento pela força da razão universal que teorias, metodologias e coletas de dados científicos poderiam ter é algo tão velho quanto a apodêixis de Sócrates e seu fabuloso segredo da demonstração matemática (LATOUR, 2001, p. 262). O que dá força aos gramáticos, apresentadores de TV e escritores de colunas em jornal é o fato de terem muito maior exposição junto à grande massa, além de argumentarem em consonância com seus anseios e crenças. Basta pensar que, se têm programas na TV e colunas regulares em jornais, conquistaram um espaço que os lingüistas ainda sonham em conquistar. Ou seja, a argumentação de Bagno soa, para o público geral, como uma fortíssima dor-de-cotovelo de quem detém o conhecimento universal da verdade racional, mas não consegue convencer ninguém de fora de seu próprio círculo a respeito dela ${ }^{4}$.

o que queremos com essa exposição de um embate que vem acontecendo desde que a lingüística clama para si o status de ciência é mostrar que há propostas recentes de mudanças que podem trazer benefícios para uma disciplina como a lingüística. A proposta de Rajagopalan deve ser discutida, certamente. E a nossa discussão do que vem acontecendo com as guerras na ciência da linguagem talvez aponte para um fato que deve ser pensado: os lingüistas, ao clamarem por um respeito que a sociedade não parece querer lhes conceder, talvez estejam agindo como o velho Sócrates, mas de uma forma anacrônica, como um Sócrates que busca por uma verdade

\footnotetext{
A dor-de-cotovelo parece tão grande que pouco ou nada se falou, por exemplo, do fato de que o maior dos sacos de pancada da lingüística contemporânea, que tem tanto um programa de TV quanto várias colunas em jornais, o "Professor" Pasquale Cipro Neto, ter sido também contrário ao projeto de lei de Aldo Rebelo nos termos em que se colocava (http:// www2.uol.com.br/linguaportuguesa/nabocadopovo/nb_comentario_lei.htm).
} 
que, desde pelo menos meados do século XX, para a ciência, não existe mais.

\section{CONCLUSÃo}

A liberdade de viver no seio de uma comunidade é obtida pela adesão às teses defendidas por essa comunidade. Essas opiniões coletivas se baseiam em valores que são identificados com a verdade. Perelman (1997, p. 252) aponta para o fato de que não existem obras contemporâneas (e a primeira edição deste importante tratado data da década de 1960) que possibilitem entender melhor os mecanismos de raciocínio no que diz respeito aos juízos de valor. Como se viu neste trabalho, o resgate do estudo da retórica em suas muitas manifestações - na ciência, na política, na filosofia - seria um empreendimento muito importante para uma compreensão mais integral do multifacetado fenômeno do discurso racional humano.

A argumentação retórica se baseia em juízos de valor tidos como importantes numa determinada sociedade. Segundo a opinião de Rajagopalan, e dos autores deste artigo, é necessário que o lingüista acesse esses valores sociais que correspondem aos anseios, crenças e opiniões do grande público leigo, que, em última instância, são os usuários pensantes da língua. Uma vez no controle de tais valores, a tarefa de se fazer ouvir pela sociedade será bem menos árdua para o cientista da linguagem. Como se vê, a lingüística crítica que Rajagopalan propõe parece se aproximar muito da tradição retórica de tentar entender e se fazer entendido por um público mais amplo.

Ao concluir esse trabalho, é possível dizer que há também, num programa de transformação da lingüística numa ciência mais acessível, a necessidade de que os lingüistas deixem de assumir uma postura elitista em relação a outras formas de se explicar os fenômenos da linguagem, i.e., a filologia e a gramática tradicional, bem como as opinióes dos "leigos" no assunto. Isso não quer dizer, no entanto, que se deva fazer ciência "para o povo" ou "leiga". Quando chegamos à questão dessas propostas finais, remetemos a discussão para as propostas de Rajagopalan e deixamos que ele tente defendê-las.

\section{RESUMO}

Este artigo discutirá as relações entre a retórica e ciência contemporânea. Ao propor a análise de tal relação, olharemos em especial para duas questões: iniciaremos o trabalho com uma história da ascensão da retórica e de sua derrocada 
ocasionada em grande parte pelo movimento da ciência moderna pós-renascentista. A partir dessa relação, a discussão contemporânea da filosofia da ciência mostrará como as relações entre ciência e política (como uma espécie de ramificação da retórica) são complexas em virtude de uma suposta incapacidade (e, talvez disséssemos, impossibilidade) de os cientistas tomarem decisões políticas adequadas e bem defendidas de modo a terem sua voz ouvida pela sociedade. Palavras-Chave: Filosofia da ciência; História da Retórica; Lingüistica crítica.

\begin{abstract}
This article discusses the relationship between rhetoric and contemporary science. By proposing the analysis of that relationship, we will be looking especially at two questions: we start with a history of the rise and fall of rhetoric, as a result of its replacement by modern, post-Renaissance science. We go on trying to argue that the contemporary philosophy of science shows that the relations between science and politics (as a branch of rhetoric) are complex due to an alleged inability of scientists to make political decisions regarding language in a way that they can be heard and trusted by society.

Key-words: Philosophy of science; History of Rhetoric; Critical linguistics.
\end{abstract}

\title{
REFERÊNCIAS
}

FEYerABEnd, Paul. Contra o Método. Tradução de: César Augusto Mortari. São Paulo: Editora da Unesp, 2007.

GRABMANN, M. Filosofia Medieval. Madrid: Editorial Labor, s/d.

KOERNER, E. F. K.; ASHER, R. E. (Eds.). Concise History of the Language Sciences: From the Sumerians to the Cognitivists. Cambridge: University Press, 1995.

KUHN, Thomas. A estrutura das revoluções científicas. São Paulo: Perspectiva, 2003.

LAKATOS, Imre. Proofs and Refutations. Cambridge: Cambridge University Press, 1976.

LATOUR, Bruno. A Esperança de Pandora. Ensaios sobre a realidade dos estudos científicos. Tradução de: Gilson César Cardoso de Sousa. Bauru-SP: EDUSC, 2001.

LYONS, John. Linguagem e Lingüística: uma introdução. Rio de Janeiro: LTC, 1987.

MoUnIN, G. História da Lingüística. Porto: Edições Despertar, 1970. 
GONÇAlves, R. T.; BECCARI, A. J. RetóRICA E CiÊnCIA: O CASO DA LingüístiCa CRítiCA

PERELMAN, C. Retóricas. São Paulo: Martins Fontes, 1997.

PERELMAN, Chaim; OLBRECHTS-TYTECA, Lucie. Tratado da Argumentação. A Nova Retórica. São Paulo: Martins Fontes, 2005.

PLATÃo. Górgias ou A Oratória. Tradução de: Jaime Bruna. São Paulo: DIFEL, 1970.

PLATO. Gorgias. London: Harvard University Press, 1991. Loeb Classical Library.

POPPER, Karl. A Lógica da Pesquisa científica. São Paulo: Cultrix, 1972.

. Conjecturas e Refutações. Brasília: Editora da Universidade de Brasília, 1982.

RAJAgopalan, Kanavillil. Por uma lingüística crítica: linguagem, identidade e questão ética. São Paulo: Parábola, 2003.

REBOUL, Olivier. Introdução à Retórica. São Paulo: Martins Fontes, 2000.

RoBINS, R. H. Pequena História da Lingüística. Rio de Janeiro: Ao Livro Técnico, 1983.

SILVA, F. Lopes da.; RAJAGOPALAN, K. (Orgs.). A lingüística que nos faz falhar: investigação crítica. São Paulo: Parábola, 2004. 